\title{
37. 都市青少年の取大作菜能力
}

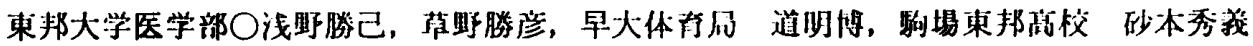

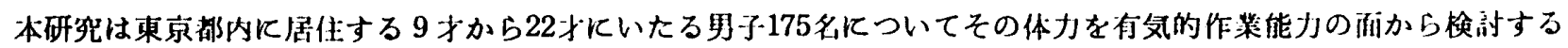
ものである.

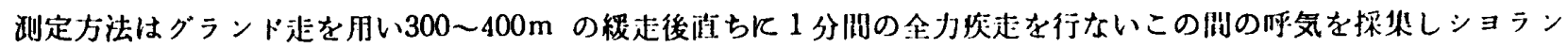

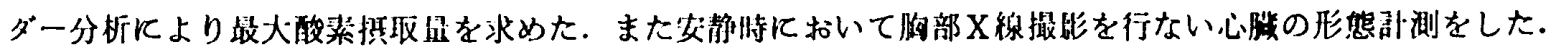

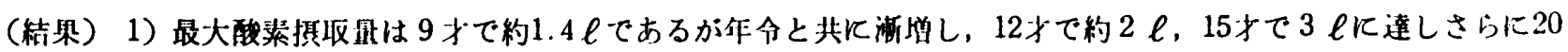

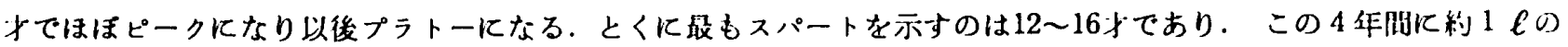

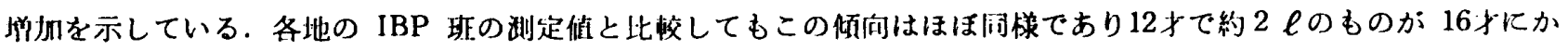

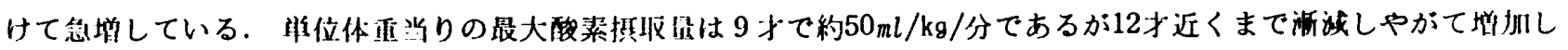

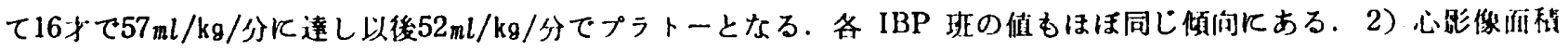

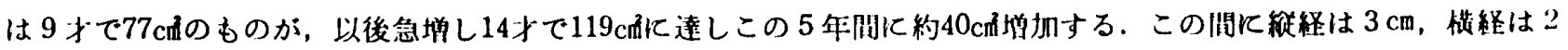

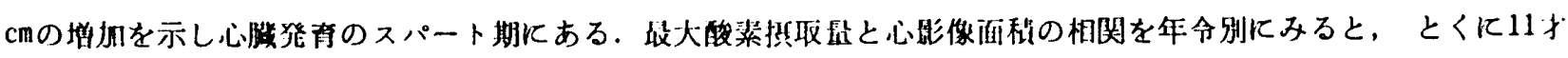

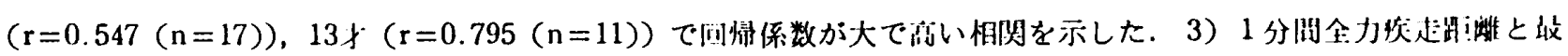

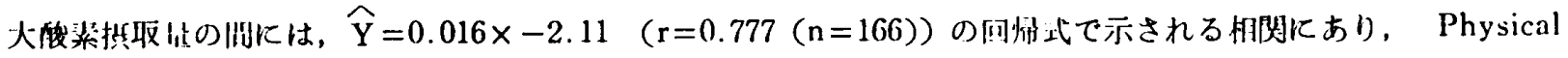
resource と Performance の莎い梱関を示した.

\section{8. 肺換谷機能に閉する研究 1 一都市中・高校生の発達について一}

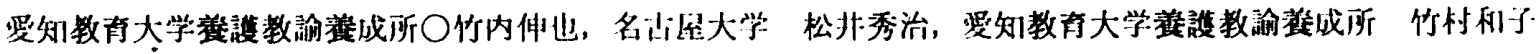

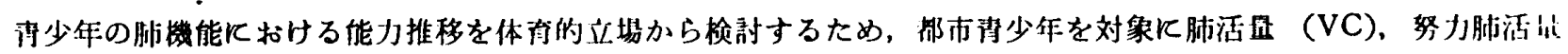

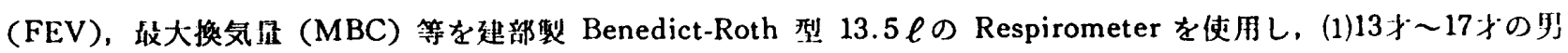

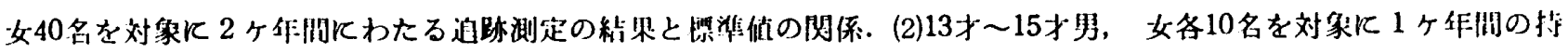

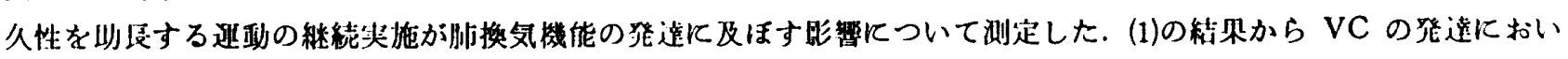

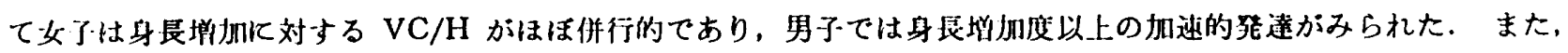

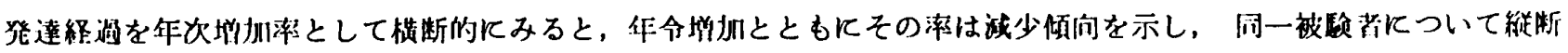

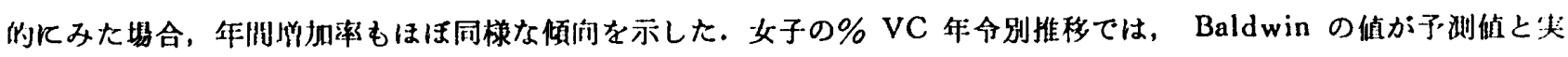

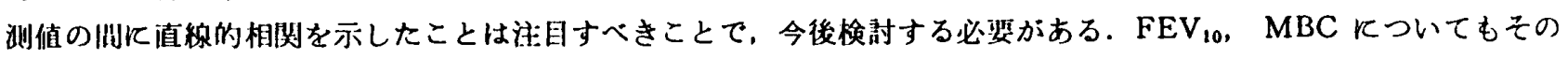

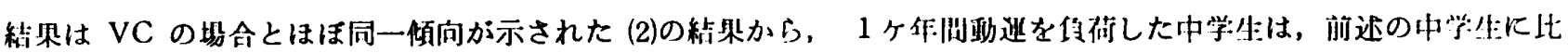

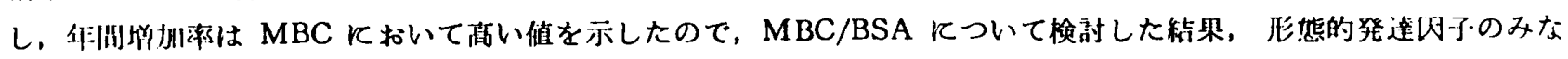

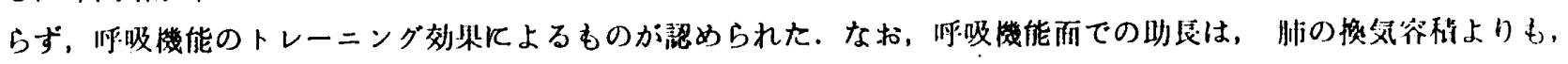

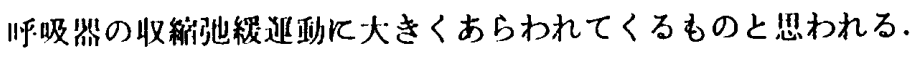

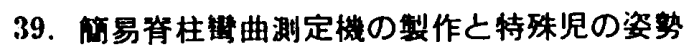

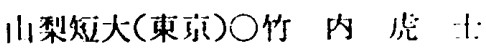

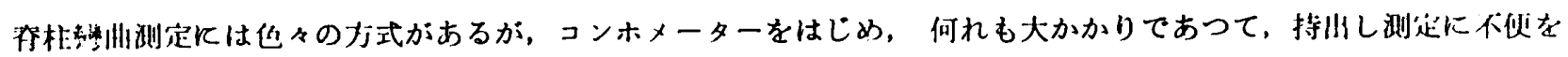

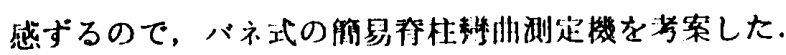

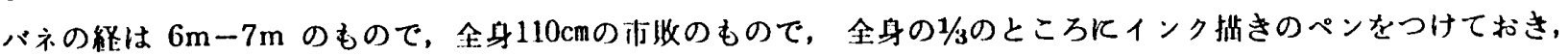

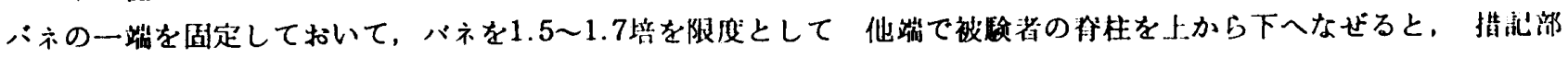

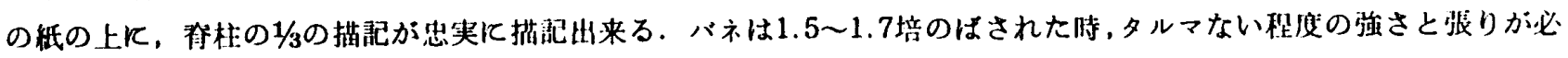

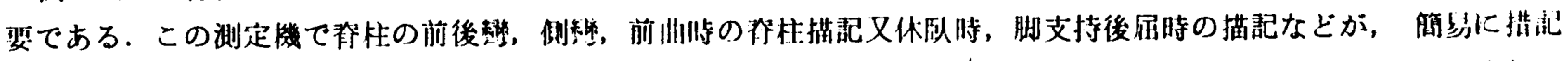

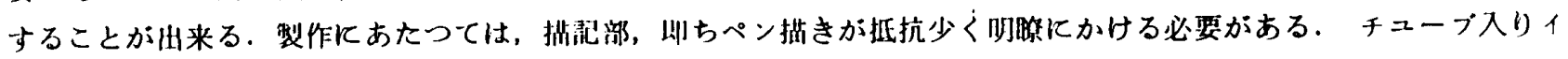

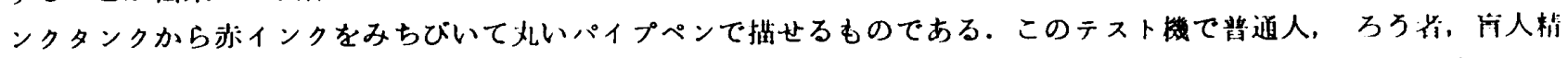

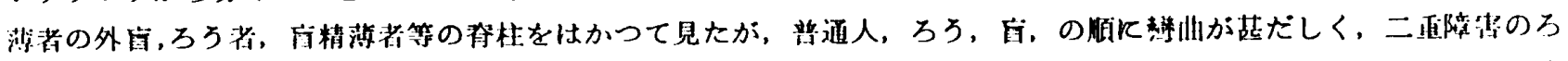

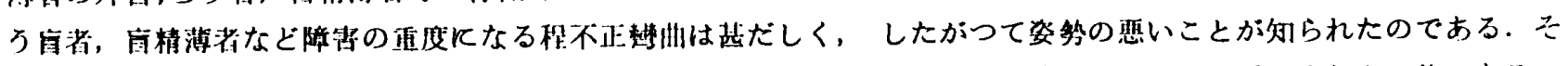

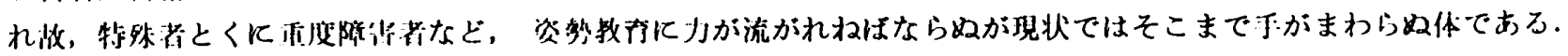

